\title{
Official ERS technical standards: Global Lung Function Initiative reference values for the carbon monoxide transfer factor for Caucasians
}

\author{
Sanja Stanojevic ${ }^{1,2}$, Brian L. Graham ${ }^{3}$, Brendan G. Cooper ${ }^{4}$, Bruce R. Thompson ${ }^{5}$, \\ Kim W. Carter ${ }^{6,7}$, Richard W. Francis (10,7 and Graham L. Hall ${ }^{6,8,9}$ on behalf of \\ the Global Lung Function Initiative TLCO working group ${ }^{10}$
}

Affiliations: ${ }^{1}$ Division of Respiratory Medicine, Hospital for Sick Children, Toronto, ON, Canada. ${ }^{2}$ Institute of Health Policy Management and Evaluation, University of Toronto, Toronto, ON, Canada. ${ }^{3}$ Division of Respirology, Critical Care and Sleep Medicine, University of Saskatchewan, Saskatoon, SK, Canada. ${ }^{4}$ Lung Function and Sleep, University Hospitals Birmingham NHS Foundation Trust, Birmingham, UK. ${ }^{5}$ Allergy Immunology and Respiratory Medicine, The Alfred Hospital and Monash University, Melbourne, Australia. ${ }^{6}$ Bioinformatics, Telethon Kids Institute, Perth, Australia. ${ }^{7}$ Centre for Child Health Research, University of Western Australia, Perth, Australia. ${ }^{8}$ Children's Lung Health, Telethon Kids Institute, Perth, Australia. ${ }^{9}$ School of Physiotherapy and Exercise Science, Curtin University, Perth, Australia. ${ }^{10} \mathrm{~A}$ full list of the Global Lung Function Initiative TLCO working group members and their affiliations can be found in the Acknowledgements section.

Correspondence: Sanja Stanojevic, Division of Respiratory Medicine, Hospital for Sick Children, Toronto, ON, Canada. E-mail: Sanja.Stanojeviclasickkids.ca

@ERSpublications

This is the largest collection of normative TLCO data and represents a step towards standardised interpretation http://ow.ly/4PcZ30dB1tn

Cite this article as: Stanojevic S, Graham BL, Cooper BG, et al. Official ERS technical standards: Global Lung Function Initiative reference values for the carbon monoxide transfer factor for Caucasians. Eur Respir J 2017; 50: 1700010 [https://doi.org/10.1183/13993003.00010-2017].

ABSTRACT There are numerous reference equations available for the single-breath transfer factor of the lung for carbon monoxide (TLCO); however, it is not always clear which reference set should be used in clinical practice. The aim of the study was to develop the Global Lung Function Initiative (GLI) all-age reference values for TLCO.

Data from 19 centres in 14 countries were collected to define TLCO reference values. Similar to the GLI spirometry project, reference values were derived using the LMS (lambda, mu, sigma) method and the GAMLSS (generalised additive models for location, scale and shape) programme in R.

12660 TLCO measurements from asymptomatic, lifetime nonsmokers were submitted; $85 \%$ of the submitted data were from Caucasians. All data were uncorrected for haemoglobin concentration. Following adjustments for elevation above sea level, gas concentration and assumptions used for calculating the anatomic dead space volume, there was a high degree of overlap between the datasets. Reference values for Caucasians aged 5-85 years were derived for T LCO, transfer coefficient of the lung for carbon monoxide and alveolar volume.

This is the largest collection of normative TLCO data, and the first global reference values available for TLCO.

This article has supplementary material available from erj.ersjournals.com

Received: Jan 032017 | Accepted after revision: June 142017

This document was endorsed by the ERS Executive Committee in July 2017 and by the American Thoracic Society, American College of Chest Physicians and Asian Pacific Society of Respirology in August 2017.

Support statement: Funding was received from the European Respiratory Society, grant number TF-2013-05. Funding information for this article has been deposited with the Crossref Funder Registry.

Conflict of interest: None declared.

Copyright OERS 2017 


\section{Background}

Lung function tests (LFTs) are important tools in the evaluation of the respiratory system. The correct interpretation of LFT results relies on the availability of appropriate reference values to help distinguish between health and disease and to assess the severity and nature of any functional impairment. Global Lung Function Initiative (GLI) multiethnic all-age reference values are available for spirometry [1]. However, there are no standardised reference values available for the second most clinically used LFT, the single-breath transfer factor of the lung for carbon monoxide (TLCO, or diffusing capacity of the lung for carbon monoxide (DLCO)). TLCO is a strong indicator of the efficiency of gas exchange in the lung, and is frequently used to inform diagnosis and monitor patients.

The European Respiratory Society (ERS) and American Thoracic Society (ATS) standards for the measurement of carbon monoxide gas transfer in the lungs were recently updated [2] and additional guidelines for interpretation of the technique are available [3]. There are several methodological aspects that may affect the interpretation of the results, with details presented in the documents. The interpretation guidelines provide a list of TLCO reference values; however, no consensus was reached, nor recommendations provided, regarding which equations were best for children, adults or those in the various ethnic groups other than to advise that laboratory directors should thoughtfully select reference values that match the values obtained from healthy individuals of appropriate background tested in their own laboratories. Changes in equipment, software and measurement techniques, combined with shifts in population characteristics, mean that some of the previously published reference values for TLCO may no longer be appropriate. The purpose of this study was to collate contemporary TLCO data from healthy individuals and derive GLI reference values for TLCO measurements.

\section{Methods}

An application was approved for an ERS task force to develop global TLCO reference values. Task force co-chairs were approved by the ERS. Task force members were scientists with experience in international guidelines, clinical experience of routine lung function testing and knowledge of gas transfer, including research publications. Potential conflicts of interest were disclosed and vetted.

\section{Data sources}

The authors of papers that published TLCO data in healthy individuals after the year 2000 were contacted and invited to share their data with the GLI TLCO task force. Of the 17 studies identified, 70\% submitted data. Details about the equipment and methodology used were collected from the published papers, or from the authors or manufacturers directly, to confirm that methods were compatible with those currently available to customers. In addition, information about the task force was circulated through international and local respiratory societies to solicit unpublished data or published studies that had not been identified. All contributing authors provided explicit permission for data to be shared with the GLI group. An online, secure data portal was developed to capture de-identified data (www.gligastransfer.org.au). Data contributors signed a data-sharing agreement, submitted details about their study population, equipment, settings and research ethics. All data were submitted using a standard data template; initial data queries were performed and contributors were asked to correct errors before data were accepted. Inclusion criteria include nonsmokers without a history of respiratory disease. All data were uncorrected for haemoglobin $(\mathrm{Hb})$ concentration. Outliers were identified using a priori criteria: forced expiratory volume in $1 \mathrm{~s}$ (FEV1) $\mathrm{z}$-scores $>5$ or $<-5$ and height $\mathrm{z}$-scores $>5$ or $<-5$ in children (aged $\leqslant 18$ years). These limits were used to identify data discrepancies and exclude subjects at the extremes of the healthy population. In addition, observations were considered to be outliers if the alveolar volume $(V \mathrm{~A})$ was smaller than the forced vital capacity (FVC). Sensitivity analyses were performed excluding individuals who were obese, where obesity was defined as body mass index (BMI) centile $>85 \%$ in children [4] and BMI $>30 \mathrm{~kg} \cdot \mathrm{m}^{-2}$ in adults (aged $>19$ years). The $\mathrm{z}$-scores derived for individuals in the full dataset and the "normal weight" dataset were compared using a paired t-test.

All TLCO data (and consequently transfer coefficient of the lung for carbon monoxide (KCO) data) were adjusted to the inspiratory oxygen partial pressure at standard barometric pressure $\left(P_{\mathrm{B}} ; 760 \mathrm{mmHg}\right.$ or $101.3 \mathrm{kPa}$ ) using the following equations $[2,5]$ :

For SI units $(\mathrm{mmol} ; \mathrm{kPa}): T_{\mathrm{LCO}}\left[P_{\mathrm{B}, \text { adjusted }}\right]=T_{\mathrm{LCO}} \cdot\left(0.505+0.00488 \cdot P_{\mathrm{B}}\right)$

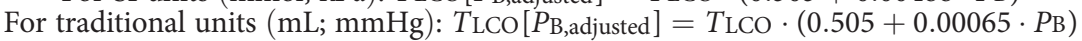

For TLCO datasets that did not provide $P \mathrm{~B}$ data $(\mathrm{n}=11)$, the altitude of the centre in which the reference values were obtained was used to estimate $P_{\mathrm{B}}$, using the following equation $[2,6]$ where $\mathrm{h}$ is the altitude 
above sea level in $\mathrm{m}$ :

$$
\begin{gathered}
P \mathrm{~B}(\mathrm{kPa})=101.3 \cdot\left(1-2.25577 \cdot 10^{-5} \cdot \mathrm{h}\right)^{5.25588} \\
P \mathrm{~B}(\mathrm{mmHg})=760 \cdot\left(1-2.25577 \cdot 10^{-5} \cdot \mathrm{h}\right)^{5.25588}
\end{gathered}
$$

In addition, we corrected corrected values in centres that used a fixed dead space correction of $150 \mathrm{~mL}$ ( $V D$,an,fixed) such that the anatomic dead space was calculated as $2.2 \mathrm{~mL} \cdot \mathrm{kg}^{-1}$ (VD,an,est) [7]:

$$
T \mathrm{LCO}^{\prime}=T \mathrm{LCO} \times\left(V_{1}-V \mathrm{D} \text {, equip }-V \mathrm{D} \text {, an, est }\right) /\left(V_{1}-V \mathrm{D} \text {, equip }-V \mathrm{D} \text {, an, fixed }\right)
$$

Complete details of the calculations can be found in the online supplementary material.

In addition, the following methodological considerations were investigated before the submitted data were combined: equipment type, breath-hold calculation, size and timing of alveolar sample collection and the year during which data were collected.

\section{Statistical analyses}

The complex nature of the relationship between body size, age, sex and lung function, particularly during periods of rapid growth, means that traditional linear regression analyses are not sufficient to derive appropriate reference values for lung function outcomes [8]. More flexible statistical modelling techniques allow the complexity of the relationship to be explained and to reflect biologically plausible relationships of lung function with age, sex and height. In the case of TLCO outcomes, we investigated body surface area as an independent predictor. Body surface area was defined as $0.007184 \cdot\left(\right.$ weight $\left.\wedge^{0.425}\right) \cdot\left(\right.$ height $\left.\wedge^{0.725}\right)[9]$. We have previously shown that the GAMLSS (generalised additive models of location shape and scale) [10] modelling approach is highly suitable to derive reference values for lung function outcomes $[1,8,11]$. The lambda, mu, sigma (LMS) method is an extension of regression analysis which includes three components: 1 ) the skewness $(\lambda)$, which models the departure of the variables from normality using a Box-Cox transformation; 2) the median $(\mu)$; and 3 ) the coefficient of variation $(\sigma)$, which models the spread of values around the median and adjusts for any nonuniform dispersion [12]. The three quantities (LMS) are allowed to change with height and/or age, to reflect changes in the distribution as people grow. We applied the LMS method using the GAMLSS package in the statistical programme $\mathrm{R}$ [10]. Goodness of fit was assessed using the Schwarz Bayesian criterion, Q-Q plots and worm plots [8].

\section{Results}

\section{Study population}

19 centres contributed data from 14 countries. Data from 12659 individuals between the ages of 4 and 91 years were collected, of which 12639 (99.8\%) had valid TLCO data available. All TLCO values that were collected using traditional units $\left(\mathrm{mL} \cdot \mathrm{min}^{-1} \cdot \mathrm{mmHg}^{-1}\right)$ were converted to SI units $\left(\mathrm{mmol} \cdot \mathrm{min}^{-1} \cdot \mathrm{kPa}^{-1}\right)$, $($ TLCO traditional units $=2.986421 \times$ TLCO SI units $)$. Overall, the mean \pm SD FEV 1 z-score for 11473 individuals with spirometry data was $0.1 \pm 1.1$, indicating a good fit with the GLI spirometry population [1]. $85 \%$ of the study population was Caucasian, with the remaining non-Caucasian population $(\mathrm{n}=1874)$ both from single sites (e.g. Japan (10\%) and Hong Kong (4.5\%)) and individuals where ethnic group was indicated as not Caucasian. Due to the lack of non-Caucasian data, TLCO reference values were developed for Caucasians only (table 1).

One centre was excluded because the breath-hold time was $5 \mathrm{~s}(\mathrm{n}=211) .58$ observations were excluded because the VA was smaller than the FVC. 11 observations were excluded because FEV1 values were $>5$ Z-scores or <-5 z-scores. 775 observations were excluded because of missing height, weight or age. Correcting TLCO for barometric pressure, such that TLCO was standardised to sea level $(P \mathrm{~B}=760 \mathrm{mmHg}$ or $101.3 \mathrm{kPa})$, on average $(95 \% \mathrm{CI})$ corrected TLCO values by $-1.5(-1.54--1.51)$ SI units (online supplementary figure S1). Adjusting the anatomic dead space decreased the TLCO on average by 0.02 (0.01-0.02) SI units (online supplementary figure S2); the correction resulted in greater relative changes in TLCO in children (1.5\%) compared with adults $(0.7 \%)$. As expected, since females weigh less than males (average $65 \mathrm{~kg}$ in females; $78 \mathrm{~kg}$ in males) the anatomic dead space correction was negative in adult males and positive in adult females.

\section{Reference values}

The population used to derive reference equations for TLCO outcomes ( $\mathrm{n}=9710)$, ranged in age from 4.5 to 91 years (median (interquartile range) 45 (26-57) years) (online supplementary figure S5); half of whom were male. Findings from preliminary modelling identified significant differences in predicted values between males $(n=4859)$ and females $(n=4851)$, therefore sex-specific equations were created for TLCO, VA 
TABLE 1 Summary of Caucasian data included in the Global Lung Function Initiative transfer factor of the lung for carbon monoxide reference values

\begin{tabular}{|c|c|c|c|c|c|c|c|c|c|}
\hline Country & Subjects & Equipment & Altitude $\mathrm{m}$ & Anatomic $V b$ & $\begin{array}{l}\text { Breath-hold } \\
\text { calculation }\end{array}$ & $\begin{array}{l}\text { Reported } \\
\text { values }\end{array}$ & $\begin{array}{c}\text { Caucasian } \\
\%\end{array}$ & $\begin{array}{c}\text { Obese } \\
\%\end{array}$ & $\begin{array}{c}\text { FEV1 } \\
\text { z-score }\end{array}$ \\
\hline New Zealand & 71 & $\begin{array}{l}\text { SensorMedics } \\
\text { Vmax Encore }\end{array}$ & 20 & Fixed & Jones-Meade & Average & 100 & 18.30 & $-0.31 \pm 0.9$ \\
\hline Australia & 605 & Other & 8 & Fixed & Jones-Meade & Average & 100 & 18.40 & $0.56 \pm 1.0$ \\
\hline Australia & 120 & $\begin{array}{l}\text { SensorMedics } \\
\text { Vmax Encore }\end{array}$ & 10 & Fixed & Jones-Meade & Average & 100 & 8.30 & $0.25 \pm 0.9$ \\
\hline The Netherlands & 543 & $\begin{array}{c}\text { Jaeger } \\
\text { MasterScreen }\end{array}$ & 13 & Fixed & Unknown & Automated & 100 & 3.00 & NR \\
\hline USA & 300 & $\begin{array}{l}\text { SensorMedics } \\
\text { Vmax Encore }\end{array}$ & 222 & $\begin{array}{l}\text { Body size } \\
\text { adjusted }\end{array}$ & Jones-Meade & Average & 100 & 9.00 & $0.03 \pm 0.9$ \\
\hline USA & 1302 & Collins & 50 & $\begin{array}{l}\text { Body size } \\
\text { adjusted }\end{array}$ & Jones-Meade & Automated & 100 & 18.10 & $0.14 \pm 0.9$ \\
\hline Greece & 942 & $\begin{array}{c}\text { Jaeger } \\
\text { MasterScreen }\end{array}$ & 460 & Fixed & Unknown & Largest & 100 & 27.60 & $0.3 \pm 0.9$ \\
\hline New Zealand & 151 & $\begin{array}{l}\text { SensorMedics } \\
\text { Vmax Encore }\end{array}$ & 10 & Fixed & Jones-Meade & Average & 100 & 4.60 & $-0.5 \pm 1.0$ \\
\hline Italy & 80 & Other & 100 & Unknown & Unknown & Unknown & 100 & NR & $0.06 \pm 0.9$ \\
\hline Italy & 3552 & $\begin{array}{l}\text { SensorMedics } \\
\text { Vmax Encore }\end{array}$ & 904 & Unknown & Unknown & Average & 100 & 25.70 & $0.2 \pm 1.0$ \\
\hline Canada & 541 & Other & Various & Unknown & Unknown & Unknown & 100 & 7.80 & $0.4 \pm 1.6$ \\
\hline
\end{tabular}

Data are presented as $\mathrm{n}$ or mean $\pm \mathrm{SD}$, unless otherwise stated. $V_{D}$ : dead space volume; FEV1: forced expiratory volume in $1 \mathrm{~s} ;$ NR: not reported.

and KCO (figure 1). Height and age were both independent predictors of TLCO, where natural logarithmic transformation of height and a spline function for age were necessary. As body surface area is correlated with alveolar surface area in children [13], we investigated body surface area as an independent predictor variable in the models. However, body surface area was highly correlated with height and therefore not included as an independent predictor.

The between-individual variability of TLCO values was age dependent, with greater variability observed in children and older individuals (figure 2). On average, the variability of TLCO was greater than that observed for FEV1. Together with the median predicted values, the between-individual variability and skewness adjustment derived from the LMS method allowed for the calculation of a lower limit of normal (LLN), as well as the calculation of z-scores (figure 1 and table 2). The resulting z-scores had a mean of zero, and a standard deviation of one, indicating good fit to the data.

\section{Sensitivity analyses}

To test whether the inclusion of overweight individuals ( $n=2630 ; 27 \%$ of total population) affects the interpretation of the results, we created reference values limiting the sample to adults with a BMI $<30 \mathrm{~kg} \cdot \mathrm{m}^{-2}$ or children with a BMI $<85 \%$ percentile $(\mathrm{n}=7771)$. The difference in $\mathrm{z}$-scores for an individual, whether overweight individuals were included or not, was -0.05 units (95\% CI $-0.050-0.048$ ). Since including overweight individuals did not bias the prediction models, we chose to include these in the final models to maximise the sample size and generalisability of the final reference values.

\section{Physiologically relevant differences}

Based on the observed variability of the TLCO we identified $0.5 \mathrm{z}$-scores as a threshold for a physiologically relevant difference. This equates to $\sim 0.3-0.8 \mathrm{mmol} \cdot \mathrm{min}^{-1} \cdot \mathrm{kPa}^{-1}$ or $10 \%$ relative change in TLCO, which was higher in older individuals. 

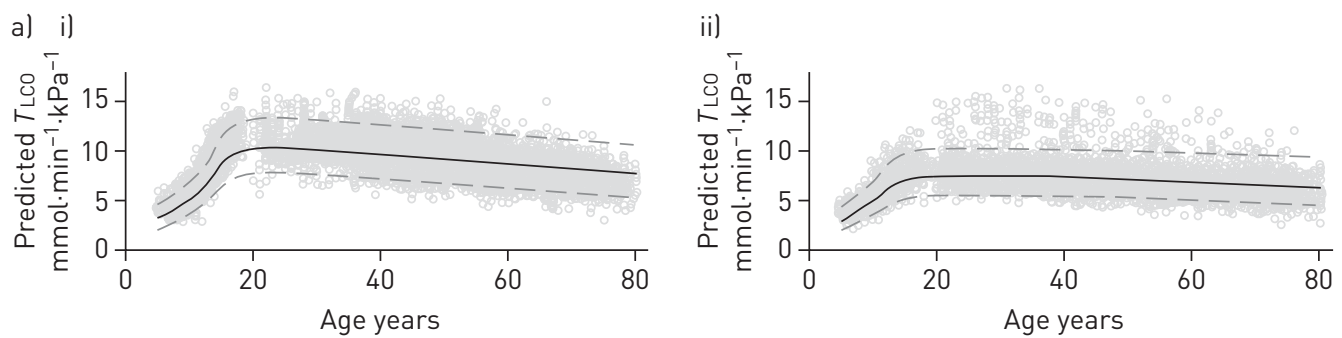

b) i)

ii)
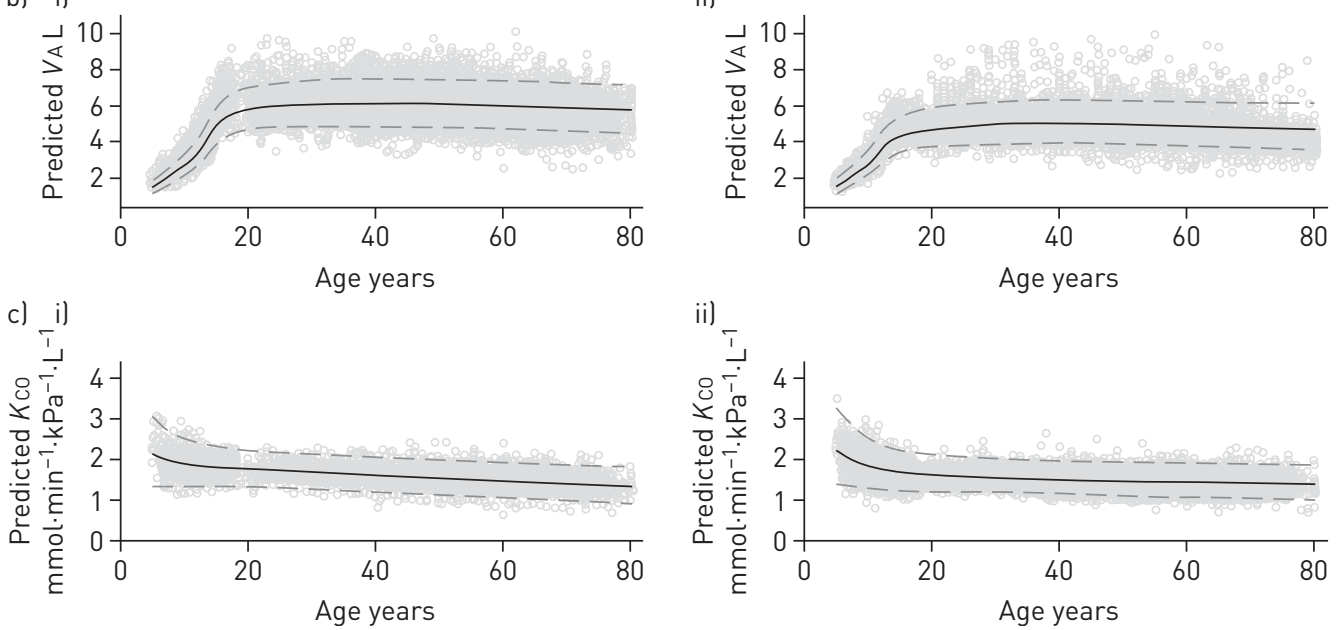

FIGURE 1 a) Predicted transfer factor of the lung for carbon monoxide ( $T$ LCo) in i) males $n=4859$ and ii) females $n=4851$; b) alveolar volume $\left(V_{A}\right)$ (at standard temperature, pressure and dry conditions) in i) males $\mathrm{n}=4793$ and ii) females $\mathrm{n}=4837$; and c) transfer coefficient of the lung for carbon monoxide ( $\mathrm{Kco}$ ) in i) males $n=4793$ and ii) females $n=4837$. Data are presented as the predicted values for age lassuming an average height at each) and $95 \%$ confidence limits. Prediction equations are overlaid on observed values. The average height used in children was the 50th height-for-age centile from Centers for Disease Control and Prevention growth charts [4], whereas in adults, the average height observed in the study population was used $1172 \mathrm{~cm}$ in males and $162 \mathrm{~cm}$ in females).

\section{Methodological differences}

We only included data where breath-hold time was reported to be $10 \mathrm{~s}$. 13 centres reported having used the Jones-Meade calculations; five reported that the calculation method was unknown. There was a minimal difference in TLCO $\mathrm{z}$-scores (mean difference $0.04,95 \%$ CI $0.0005-0.08 ; n=9630$ ) between those that used the Jones-Meade method and those that did not report a method; these differences were not considered to be clinically or physiologically relevant. Most data were collected on commercial equipment (SensorMedics (29.5\%; five centres), Jaeger (29.4\%; five centres) and Collins (11.8\%; two centres)), while

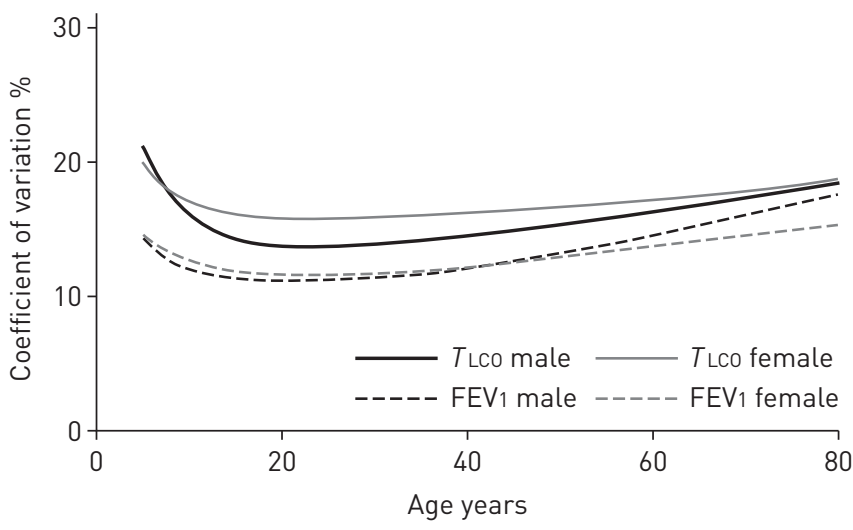

FIGURE 2 Between-subject variability of transfer factor of the lung for carbon monoxide (TLCo) across age; the variability of forced expiratory volume in $1 \mathrm{~s}\left(\mathrm{FEV}_{1}\right)$ in males and females is included as a comparator. 
TABLE 2 The corrected equations for predicted values for the median (M), the variability around the median (S) and the skewness (L) for each of the $T_{\text {LCo }}$ test outcomes (transfer factor of the lung for carbon monoxide $\left(T_{\mathrm{LCO}}\right)$, transfer coefficient of the lung for carbon monoxide $\left(K_{\mathrm{CO}}\right)$ and alveolar volume $\left.\left(V_{\mathrm{A}}\right)\right)$

M S S L

\section{Male}

$T$ Lo $\mathrm{mmol} \cdot \mathrm{min}^{-1} \cdot \mathrm{kPa}^{-1}$

$D_{\mathrm{LCO}} \mathrm{mL} \cdot \mathrm{min}^{-1} \cdot \mathrm{mmHg}^{-1}$

$\exp (-8.129189+2.018368 \cdot \ln ($ height $)-0.012425 \cdot \ln ($ age $)+$ Mspline $)$ $\exp (-7.034920+2.018368 \cdot \ln ($ height $)-0.012425 \cdot \ln ($ age $)+$ Mspline $)$

$K_{\mathrm{CO}}$ (SI) $\mathrm{mmol} \cdot \mathrm{min}^{-1} \cdot \mathrm{kPa}^{-1} \cdot \mathrm{L}^{-1}$

$K_{\text {CO }}$ (trad) $\mathrm{mL} \cdot \mathrm{min}^{-1} \cdot \mathrm{mmHg}^{-1} \cdot \mathrm{L}^{-1}$

$\exp (2.994137-0.415334 \cdot \ln ($ height $)-0.113166 \cdot \ln ($ age $)+$ Mspline) $\exp (4.088408-0.415334 \cdot \ln ($ height $)-0.113166 \cdot \ln ($ age $)+$ Mspline $)$

$\exp (-1.98996+0.03536 \cdot \ln ($ age $)+$ Sspline $)$

$V_{\mathrm{A}} \mathrm{L}$

$\exp (-11.086573+2.430021 \cdot \ln ($ height $)+0.097047 \cdot \ln ($ age $)+$ Mspline $)$

$\exp (-1.98186+0.01460 \cdot \ln ($ age $)+$ Sspline $)$

0.67330

$\exp (-2.20953+0.01937 \cdot \ln ($ age $)+$ Sspline $)$

0.62559

\section{Female}

$T_{\mathrm{LCO}} \mathrm{mmol} \cdot \mathrm{min}^{-1} \cdot \mathrm{kPa}^{-1}$

$D_{\text {LCO }} \mathrm{mL} \cdot \mathrm{min}^{-1} \cdot \mathrm{mmHg}^{-1}$

$K_{\text {CO }}$ (SI) $\mathrm{mmol} \cdot \mathrm{min}^{-1} \cdot \mathrm{kPa}^{-1} \cdot \mathrm{L}^{-1}$

$K_{\mathrm{CO}}$ (trad) $\mathrm{mL} \cdot \mathrm{min}^{-1} \cdot \mathrm{mmHg}^{-1} \cdot \mathrm{L}^{-1}$

$\exp (-6.253720+1.618697 \cdot \ln ($ height $)-0.015390 \cdot \ln ($ age $)+$ Mspline $\exp (-5.159451+1.618697 \cdot \ln ($ height $)-0.015390 \cdot \ln ($ age $)+$ Mspline $)$

$\exp (4.037222-0.645656 \cdot \ln ($ height $)-0.097395 \cdot \ln ($ age $)+$ Mspline $)$ $\exp (5.131492-0.645656 \cdot \ln ($ height $)-0.097395 \cdot \ln ($ age $)+$ Mspline)

$\exp (-9.873970+2.182316 \cdot \ln ($ height $)+0.082868 \cdot \ln ($ age $)+$ Mspline $)$

$V_{\mathrm{A}} \mathrm{L}$$$
\text { cying coefficients from the look-up tables provided in the supplementary material. Height and age are expressed as cm and }
$$

Mspline Sspline correspond to the age-varying coefficients from the look-up tables provided in the supplementary material. Height and age are expressed as cm and years, respectively.

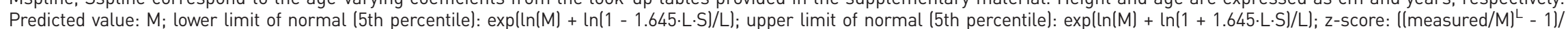

(L.S); \% predicted: (measured/M).100; exp: natural exponential; In: natural logarithm. This table has been amended in the article originally published in the September 2017 issue of the European Respiratory Journal; further details can be found in the author correction article published in October 2020. 
a)
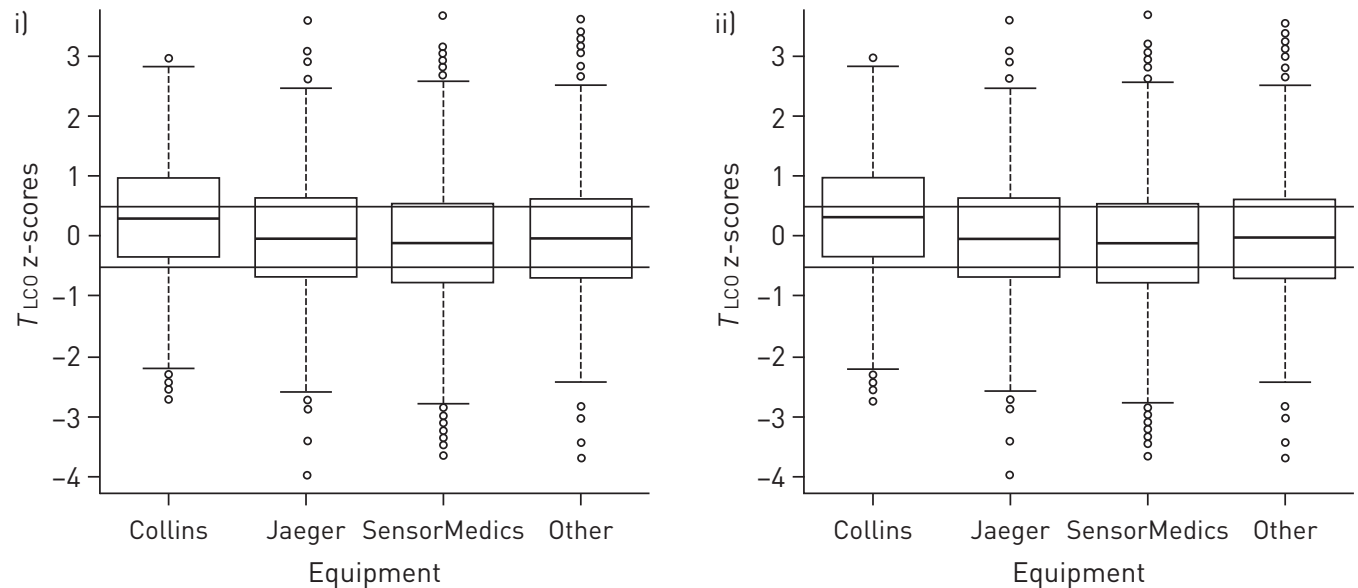

b)
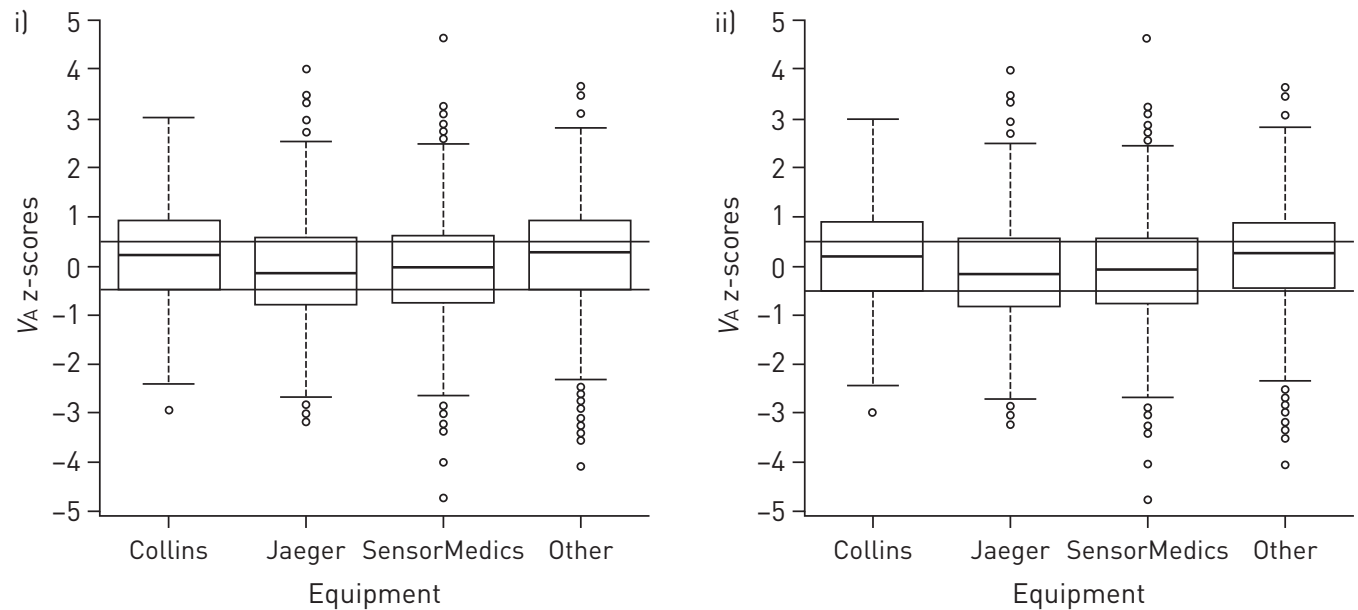

c)
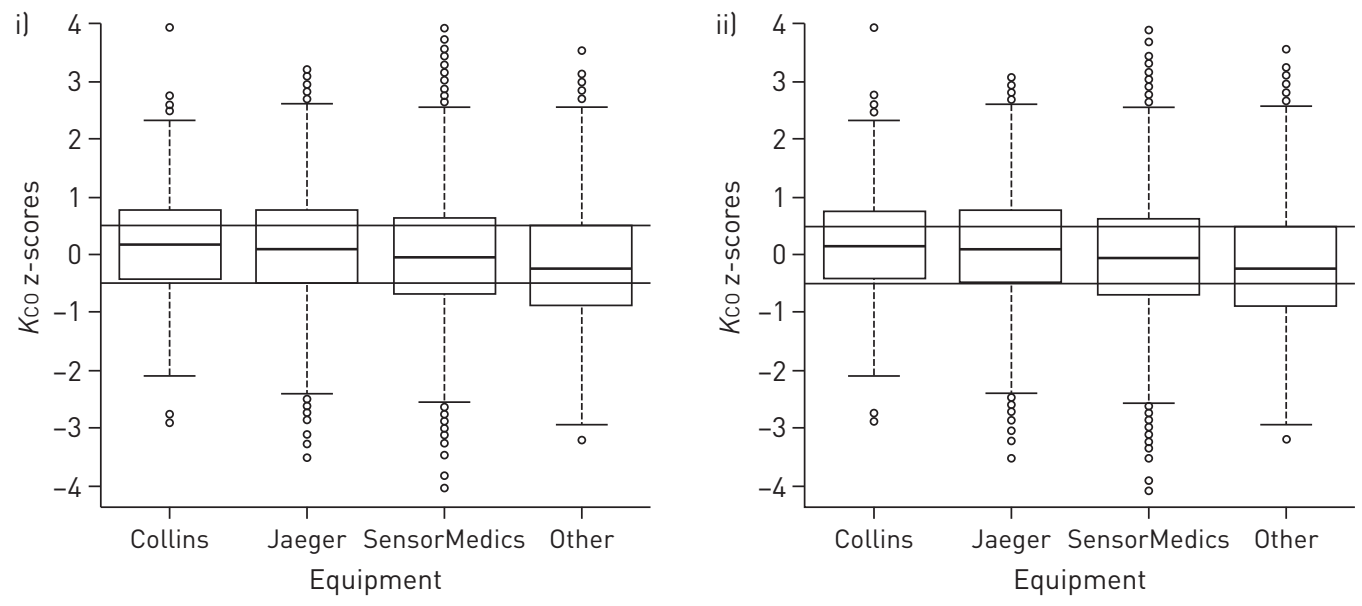

FIGURE 3 Differences in a) transfer factor of the lung for carbon monoxide ( $T L \mathrm{CO}$ ) in i) males $\mathrm{n}=4859$ and ii) females $n=4851$; b) alveolar volume $\left(V_{A}\right)$ in i) males $n=4793$ and ii) females $n=4837$; and c) transfer coefficient of the lung for carbon monoxide ( $K \mathrm{co}$ ) z-scores in i) males $n=4793$ and ii) females $n=4837$ according to equipment in Caucasian subjects. Boxplots indicate the median value (centre line); interquartile range (box) and minimum and maximum values, excluding outliers greater than three times the lower quartile (error bars).

26.7\% (six centres) reported "other" equipment not listed on our predefined list of commercial devices and one centre did not report the equipment type. There were minimal differences in TLCO between different equipment types, which was consistent between males and females (figure 3). Four centres reported using 

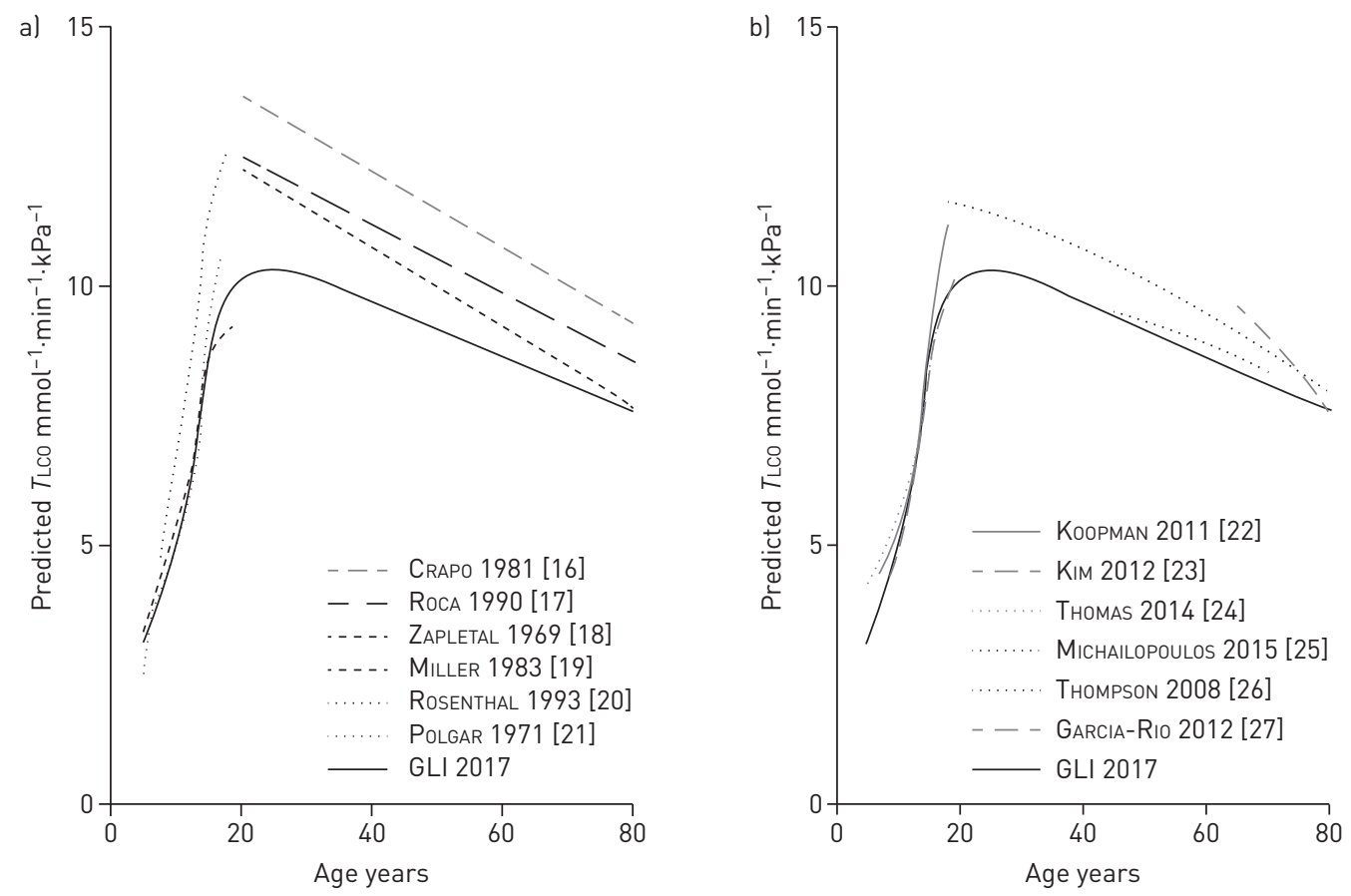

FIGURE 4 Comparison of transfer factor of the lung for carbon monoxide ( $T L C O$ ) reference equations to the current Global Lung Function Initiative (GLI) equations. Equations found in a) most commercially available equipment and b) more recently published studies.

19\% oxygen, and TLCO values were corrected using the equation by KANNER and CRAPO [14] (online supplementary figure S3). In the majority of centres, TLCO values were reported as an average of acceptable tests (eight centres, 47.1\%). Others reported the largest value (three centres, $17.7 \%$ ), values generated by equipment software (three centres, 17.7\%), did not report the method used (two centres, 11.8\%) or selected "other" (one centre, 5.9\%). The method of reporting results did not lead to physiologically relevant differences in TLCO. The reporting of values was equipment-specific, except for the case of Jaeger and "other", where reporting of values was centre-specific. A summary of the original and final corrected TLCO values used to derive the reference values is presented in online supplementary figure S4.

Haemoglobin correction of TLCo outcomes

All of the TLCO data included in this healthy population were uncorrected for Hb. However, TLCO is dependent on the amount of $\mathrm{Hb}$ in the pulmonary capillary bed. To gauge the potential effect of variation

TABLE 3 Comparison of predicted values for individuals using available transfer factor of the lung for carbon monoxide ( $T$ LCO) reference values

\begin{tabular}{|c|c|c|c|}
\hline \multirow{2}{*}{$\begin{array}{l}\text { First author, year } \\
\text { [reference] }\end{array}$} & \multicolumn{3}{|c|}{ TLCo $\mathrm{mmol} \cdot \mathrm{min}^{-1} \cdot \mathrm{kPa}^{-1}$} \\
\hline & $\begin{array}{c}\text { 178-cm, 64-year-old } \\
\text { male }\end{array}$ & $\begin{array}{c}\text { 178-cm, 20-year-old } \\
\text { male }\end{array}$ & $\begin{array}{c}150-\mathrm{cm}, 10 \text {-year-old } \\
\text { male }\end{array}$ \\
\hline GLI, 2017 & 9.2 & 10.9 & 6.4 \\
\hline CRAPO, 1981 [16] & 11.3 & 14.5 & \\
\hline MILLER, 1983 [19] & 9.2 & 12.6 & \\
\hline RocA, 1990 [17] & 10.3 & 13.3 & \\
\hline Gutierrez, 2004 [28] & 8.3 & 10.5 & \\
\hline Thомрsоn, 2008 [26] & 9.3 & 10.8 & \\
\hline KoOPMAN, 2011 [22] & & & 6.4 \\
\hline КІм, 2012 [23] & & & 6.0 \\
\hline
\end{tabular}

The list of equations is not meant to be comprehensive, rather it provides a range of differences that might be expected. GLI: Global Lung Function Initiative. 
TABLE 4 Summary of the practical recommendations for applying Global Lung Function Initiative transfer factor of the lung for carbon monoxide ( $T L C O$ ) reference values

\section{Barometric pressure (altitude) \\ Anatomic dead space}

$\mathrm{Hb}$
TLCO and Kco values should be adjusted to standard pressure $1101.3 \mathrm{kPa}$ or $760 \mathrm{mmHg}$ ) prior to calculation of predicted values

Anatomic dead space should be either measured from the tracer gas washout or estimated using body size

$T$ LCO values should be uncorrected for $\mathrm{Hb}$; $\mathrm{Hb}$ levels should be considered in the interpretation

$\mathrm{Hb}$ : haemoglobin; Kco: transfer coefficient of the lung for carbon monoxide.

from the standard reference values of $8.31 \mathrm{mmol} \cdot \mathrm{L}^{-1}\left(134 \mathrm{~g} \cdot \mathrm{L}^{-1}\right)$ for females and children and $9.06 \mathrm{mmol} \cdot \mathrm{L}^{-1}\left(146 \mathrm{~g} \cdot \mathrm{L}^{-1}\right)$ for adult males, we used the National Health and Nutrition Examination Survey (NHANES) III age-, sex- and ethnicity-specific reference values for $\mathrm{Hb}$ [15] to calculate an expected $\mathrm{Hb}$ level for all individuals and then calculated TLCO adjusted for the predicted Hb level using $T \mathrm{LCO}_{\mathrm{Hb}}=T \mathrm{LCO} \times(1.7 \times \mathrm{Hb} /(0.7 \times \mathrm{Hb}$ reference $+\mathrm{Hb}))$ [2]. There was no difference in the $\mathrm{z}$-scores calculated using the Hb-corrected TLCO reference values versus the Hb-uncorrected TLCO reference values (mean difference $<0.0001$ ). In addition, adjusting for $\mathrm{Hb}$ as a covariate in the prediction model did not improve the overall model fit, nor was age- and sex-predicted $\mathrm{Hb}$ an independent predictor of TLCO.

\section{Ethnic differences}

$85 \%$ of the data were from Caucasians, and there were insufficient data from any other ethnic group to derive all-age equations, therefore the final prediction equations are limited to Caucasians. The majority of the non-Caucasian individuals were adults from Japan (10\%). TLCO Z-scores calculated based on Caucasian data were on average $-0.1 \pm 1.4 \mathrm{z}$-scores lower than for Caucasians, with a pattern of higher TLCO z-score values in younger individuals. For $V A$, the average $\mathrm{z}$-score was $0.31 \pm 1.1$ units higher than that for Caucasians. TLCO data collected in adult males from Hong Kong were $-0.25 \pm 1.2 \mathrm{z}$-scores lower than Caucasians, with lower values in older individuals.

\section{Comparison with existing reference values}

Compared with many earlier TLCO reference values for adults, the GLI TLCO reference values are noticeably lower (figure $4 \mathrm{a}$ ); however, compared with more-recently published equations, many of which are included in the GLI dataset, the new GLI TLCO equations are quite comparable (figure $4 \mathrm{~b}$ ). For an individual, interpretation of results can be quite different depending on which equation is used (table 3 ).

\section{Discussion}

These GLI reference values for TLCO are the largest and first internationally representative collection of data from healthy Caucasian individuals for this commonly used pulmonary function test. Development of the GLI reference values has taken into consideration several of the methodological and equipment differences that are known to influence TLCO values and presents a standardised way to interpret outcomes. Spirometry z-scores for the population used to derive the TLCO equations fit the GLI 2012 spirometry population very well. However, the present TLCO equations are limited to Caucasians, therefore additional data for non-Caucasians are urgently needed to increase the generalisability of these findings.

Similar to prediction equations for spirometry, sex, age and height were independent and significant predictors of TLCO. The TLCO equations are therefore sex-specific and describe a multiplicative relationship with age and height. Previous studies have used weight and/or surface area as predictor variables for TLCO [26]. In our analysis, prediction equations were virtually identical whether overweight individuals were included or excluded from the dataset; we chose to use the more inclusive, larger dataset in the final prediction equations. Furthermore, height and surface area were highly correlated and therefore surface area was not included in the prediction model.

Previous studies have shown large differences in the predicted values between different prediction equations [23, 26]. Many older publications reporting TLCO reference values were based on outdated equipment that is no longer available, and which often applied different assumptions and algorithms and using different gas concentrations. More recently, reference values have become available for TLCO in children $[22,23]$, which are included in the GLI dataset. The GLI equations have the advantage of seamlessly continuing into adulthood, a significant advantage given the large discontinuity between previously published paediatric and adult equations (figure $4 \mathrm{~b}$ ). 
There were insufficient data to create multiethnic reference values. The largest sample of non-Caucasian data were from Japanese adults, who had lower TLCO z-scores on average and were biased by age. Older Japanese individuals had lower TLCO z-scores, which may partially be explained by secular changes in socioeconomic and general health conditions that have affected body frames and leg length in Japan; this hypothesis requires further investigation [29].

The 2005 ATS/ERS standards on interpretation of lung function state that for each lung function index, values below the 5th percentile of the frequency distribution of values measured in the reference population are considered to be below the expected "normal range" [3]. This is often referred to as the LLN. Values at the upper end of the distribution are generally considered to be physiological variants, and as such, there is no upper limit of normal. It may be argued that an upper limit of normal is required for TLCO, since conditions such as polycythaemia, left-to-right cardiac shunt or alveolar haemorrhage (e.g. Goodpasture's syndrome) can result in higher than expected values. In addition, some authors state that asthma increases TLCO [30], but not usually to a great extent. Other factors that increase pulmonary capillary blood volume, such as exercise or a decrease in intrathoracic pressure, such as during a Mueller manoeuvre, will also increase TLCO. Cases of left-to-right cardiac shunt or acute alveolar haemorrhage are very rarely seen upon pulmonary function testing and TLCO is not a standard test for their diagnosis. For these reasons, the LLN for TLCO provided in these reference values is the 5th percentile. Similarly, the 5th percentile is used for $V A$.

Although the same arguments can be applied to reference values for KCO, there is a need to consider the effect of VA on KCO. Failure to inhale completely to total lung capacity will reduce TLCO, but KCO will be increased. The KCO from a submaximal inhalation will be overestimated when compared to the reference value, yielding a normal or above-normal KCO when the TLCO is actually reduced [31]. Thus, the reference value and the normal range for KCO are only valid when the VA is normal. The LLN reported here for KCO is the 5th percentile, but interpreters must use caution when the $V$ A differs from the reference value. An individual with a low TLCO and a low VA may have a KCO that erroneously lies within the normal range $[3,31]$.

As expected, the coefficient of variation is higher for TLCO than FEV1, since TLCO is dependent on several factors in addition to size of the lungs (figure 2). As seen in figure 2, the between-individual variability of TLCO in females was greater than that observed in males. This sex-related difference in the coefficient of variation may be due to the previously observed mean changes of $13 \%$ in TLCO in females during the menstrual cycle [32]. The highest value was observed just before the menses, and the lowest on the third day of menses. This mechanism is further supported by the GLI all-age analysis of the combined datasets which shows that the sex-related difference in TLCO coefficient of variation is minimal in younger (aged $<10$ years) individuals, where the females were presumably prepubescent, and in the older (aged $>55$ years) individuals, where the females were presumably postmenopausal. For both males and females, alterations in lung structure and heterogeneity in ventilation that occur as the lung ages may reduce TLCO in some persons, which in turn, may contribute to an increase in the variation of TLCO in older adults [33].

\section{Methodological differences}

The GLI TLCO were limited to studies that used modern equipment and standardised methodology, although we did not apply specific exclusions based on equipment or methodology other than the 5-s breath-hold. Where possible, we corrected data for altitude, oxygen concentration and anatomic dead space to standardise the interpretation of results between centres.

Within the data collected for the GLI task force, two key methodological differences between datasets were identified: 1) the method for correcting for dead space and 2) the altitude of the sites, both of which have a direct impact on TLCO values. The updated standards $[2,34]$ note that the equipment dead space (filter, valve and mouthpiece) are not negligible (up to $350 \mathrm{~mL}$ ) and should be considered in combination with anatomic dead space when determining TLCO values. In adults, the combined dead space may be relatively small compared to the size of the lungs, but the likelihood of contamination of the sample volume is higher and may result in lower VA and TLCO values. However, the effect of dead space could be larger in smaller individuals and especially in children where the combined equipment and anatomical dead space is relatively large compared to the size of their lungs. Within the GLI dataset, two different methods for estimating the anatomic dead space were used: 1) fixed volume of $150 \mathrm{~mL}$ and 2) estimated based on body size (see the online supplementary material for details). We observed that paediatric datasets that had a fixed dead space volume underestimated the TLCO. When TLCO values were adjusted based on estimated dead space relative to body weight, the differences between datasets was minimised. Secondly, we observed that TLCO was higher for sites that were not at sea level. A contributory factor to the increase in TLCO at these sites could be the lower alveolar oxygen tension due to the decreased $P \mathrm{~B}$ with increasing altitude. Using the altitude of the site as a proxy for $P \mathrm{~B}$, we corrected all $T \mathrm{LCO}$ data to $101.3 \mathrm{kPa}(760 \mathrm{mmHg})$. 
Since KCO was calculated as TLCO/VA, KCO was also corrected for standard pressure. Although the use of a fixed $P_{\mathrm{B}}$ for a given site based on its altitude corrects for the mean effect of $P \mathrm{~B}$, it does not correct for the day-to-day variations that occur in $P \mathrm{~B}$ due to high and low pressure cells, which are rarely outside the range of $\pm 3.33 \mathrm{kPa}( \pm 25 \mathrm{mmHg}$ ). These pressure changes translate to a variation of up to $\pm 1.5 \%$ in TLCO, which contributes to between-individual variation in the combined datasets. The altitude correction is based on experimental evidence which measured the change in TLCO with altitude, and thus does not assume any underlying physiological abnormality [5]. Finally, while we adjusted for altitude of the site, we could not adjust for the individual's $\mathrm{Hb}$ level, and there may be residual effects of higher altitude on Hb levels.

TLCO is dependent on both the overall surface area and thickness of the alveolar-capillary membrane and the amount of $\mathrm{Hb}$ in the pulmonary capillary blood. As carbon monoxide competes with oxygen for binding with $\mathrm{Hb}$, TLCO is also dependent on the pulmonary capillary oxygen concentration. Ruíz-Argüelles et al. [35] showed that $\mathrm{Hb}$ in an adult Mexican population living at an altitude of $2670 \mathrm{~m}$ was $5 \mathrm{~g} \cdot \mathrm{L}^{-1}$ higher in adult males and $15 \mathrm{~g} \cdot \mathrm{L}^{-1}$ higher in adult females compared to the Mexican population living at sea level. Laboratories at $>1000 \mathrm{~m}$ above sea level need to consider $\mathrm{Hb}$ and be aware that further adjustments may be necessary. Ideally, individual TLCO measurements should be corrected for the individual's $\mathrm{Hb}$ levels $[3,34]$, since $\mathrm{Hb}$ concentration will affect the rate of carbon monoxide uptake; but few clinical pulmonary function laboratories routinely make this correction. Only four of the available datasets provided $\mathrm{Hb}$ values, and therefore we could not derive Hb-corrected TLCO reference values. The 2005 ATS/ERS statement recommends that predicted TLCO values are corrected to standard Hb values using the equation derived by COTES and colleagues [36, 37]; however, the correction is dependent on the assumptions that the alveolar partial pressure of oxygen is $14.63 \mathrm{kPa}(110 \mathrm{mmHg})$ and that the ratio of the membrane diffusing capacity to pulmonary capillary blood volume times the reaction rate of carbon monoxide with oxyhaemoglobin is $0.7 \mathrm{~mL}^{-1} \cdot \mathrm{min}^{-1} \cdot \mathrm{mmHg}^{-1} \cdot \mathrm{mL}$-blood. While these equations provide a simple correction to $146 \mathrm{~g} \cdot \mathrm{L}^{-1}$ for males aged $\geqslant 15$ years and $134 \mathrm{~g} \cdot \mathrm{L}^{-1}$ for females and children, measures of $\mathrm{Hb}$ levels in the general USA population (NHANES III) were substantially different from these fixed reference values, especially in children, males and non-Caucasians $[15,38]$. White males have peak $\mathrm{Hb}$ of $155 \mathrm{~g} \cdot \mathrm{L}^{-1}$ at the age of 30 years, while both male and female African-American subjects have Hb levels $\sim 8-10 \%$ lower than white subjects. Furthermore, the relationship between TLCO and Hb in heathy individuals may not reflect that observed in disease groups, and thus there is a need to define clinically relevant correction factors for $\mathrm{Hb}$.

\section{Implementation}

The updated TLCO standards recommend that TLCO is reported as the measured value, as well as the value adjusted to standard pressure [39]. Furthermore, table 4 summarises the additional adjustments that should be made by users prior to applying the GLI TLCO reference values. The format of the TLCO equations and look-up tables is identical to the GLI spirometry equations, which will facilitate implementation into many devices which already have the GLI spirometry equations programmed. The prediction equations (table 2) and look-up tables are provided in both SI and traditional units (www. lungfunction.org), and a worked example is included in the online supplementary material. Similar to previous GLI tools, researchers, clinicians and manufactures can access individual calculators, and other tools for applying these equations for large research datasets are also available at www.lungfunction.org.

\section{Limitations}

While the GLI TLCO data represents the largest collection of normative data for TLCO, the lack of data from non-Caucasians limits the generalisability. The extent to which ethnic differences for TLCO occur is unclear and could not be explored in the current GLI dataset due to the limited sample of non-Caucasians. Some differences were observed between different equipment types and between centres, but these were generally within the limits of physiological variability. In a few cases, results were outside the physiologically defined limits and warrant further investigation, since it was not possible to ascertain whether differences within the current dataset were attributable to equipment, population or methodology. Since many of the causes of potential differences in TLCO affect results in opposite directions, between-individual variability would be expected to increase, thereby underestimating the LLN, but this should not affect the predicted value. The adjustments traditionally used on TLCO to correct for oxygen tension, barometric pressure and $\mathrm{Hb}$ levels have been challenged. The correction for barometric pressure (or altitude) is based on scant data [5] and may not be linear [39]. Further research on the effect of altitude on TLCO is well warranted.

\section{Conclusions}

GLI reference values for TLCO (2017) provide a generalisable reference to standardise the reporting and interpretation of TLCO data for Caucasians. Data collection in non-Caucasians and future validation with 
measurements made using contemporary equipment and updated ATS/ERS recommendations are necessary.

\section{Acknowledgements}

The Global Lung Function Initiative (GLI) TLCO working group consists of the authors and the following additional members. Philip Quanjer (Rotterdam, the Netherlands), Janet Stocks (London, UK), Darcy Marciniuk (Saskatoon, SK, Canada), Mary Sau Man Ip (Hong Kong, China) and Juan-Carlos Vazquez (Mexico City, Mexico).

Contributors to the GLI TLCO database were Emma Smith (Brisbane, Australia), Debbie Zagami (Queensland, Australia), Stefan Kostianev (Plovdiv, Bulgaria), Winfried Baden (Tübingen, Germany), Pavlos Michailopoulos (Thessaloniki, Greece), Mary Sau Man Ip (Hong Kong, China), Vito Brusasco (Genoa, Italy), Masaru Kubota (Sagamihara, Japan), Laura Gochicoa (Texcoco, Mexico), Hubertus Arets (Utrecht, the Netherlands), Bruce Thompson (Melbourne, Australia), Ivo van der Lee (Hoofddorp, the Netherlands), Andrew Collingwood (Auckland, New Zealand), Piotr Boros (Warsaw, Poland), Linda Ekerljung (Gothenburg, Sweden), Kim Young-Jee (Indianapolis, IN, USA) and Gerald Zavorsky (Atlanta, GA, USA).

\section{References}

1 Quanjer PH, Stanojevic S, Cole TJ, et al. Multi-ethnic reference values for spirometry for the 3-95-yr age range: the global lung function 2012 equations. Eur Respir J 2012; 40: 1324-1343.

2 Graham BL, Brusasco V, Burgos F, et al. Executive summary: 2017 ERS/ATS standards for single-breath carbon monoxide uptake in the lung. Eur Respir J 2017; 49: 16E0016.

3 Pellegrino R, Viegi G, Brusasco V, et al. Interpretative strategies for lung function tests. Eur Respir J 2005; 26 : 948-968.

4 Kuczmarski R, Ogden CL, Guo S, et al. CDC Growth Charts. Atlanta, National Center for Health Statistics, 2000.

5 Gray G, Zamel N, Crapo RO. Effect of a simulated 3,048 meter altitude on the single-breath transfer factor. Bull Eur Physiopathol Respir 1986; 22: 429-431.

6 National Oceanic and Atmospheric Administration. Pressure Altitude Calculator. www.weather.gov/epz/wxcalc pressurealtitude Date last accessed: November 11, 2016.

$7 \quad$ Cotes JE. Lung Function. 5th edn. London, Blackwell Scientific Publications, 1993.

8 Stanojevic S, Wade A, Stocks J, et al. Reference ranges for spirometry across all ages: a new approach. Am J Respir Crit Care Med 2008; 177: 253-260.

9 Dubois D, Dubois E. A formula to estimate the approximate surface area if height and weight be known. Arch Intern Med 1916; 17: 863-871.

10 Rigby RA, Stasinopoulos DM. Smooth centile curves for skew and kurtotic data modelled using the Box-Cox power exponential distribution. Stat Med 2004; 23: 3053-3076.

11 Cole TJ, Stanojevic S, Stocks J, et al. Age- and size-related reference ranges: a case study of spirometry through childhood and adulthood. Stat Med 2009; 28: 880-898.

12 Cole TJ, Green PJ. Smoothing reference centile curves: the LMS method and penalized likelihood. Stat Med 1992; 11: 1305-1319.

13 Thurlbeck WM. Postnatal human lung growth. Thorax 1982; 37: 564-571.

14 Kanner RE, Crapo RO. The relationship between alveolar oxygen tension and the single-breath carbon monoxide diffusing capacity. Am Rev Respir Dis 1986; 133: 676-678.

15 Hollowell JG, van Assendelft OW, Gunter EW, et al. Hematological and iron-related analytes - reference data for persons aged 1 year and over: United States, 1988-94. Vital Health Stat 2005; 11: 1-156.

16 Crapo RO, Morris AH. Standardized single breath normal values for carbon monoxide diffusing capacity. Am Rev Respir Dis 1981; 123: 185-189.

17 Roca J, Rodriguez-Roisin R, Cobo E, et al. Single-breath carbon monoxide diffusing capacity prediction equations from a Mediterranean population. Am Rev Respir Dis 1990; 141: 1026-1032.

18 Zapletal A, Motoyama EK, Van De Woestijne KP, et al. Maximum expiratory and airway conductance in children and adolescents. J Appl Physiol 1969; 26: 308-316.

19 Miller A, Thornton JC, Warshaw R, et al. Single breath diffusing capacity in a representative sample of the population of Michigan, a large industrial state. Predicted values, lower limits of normal, and frequencies of abnormality by smoking history. Am Rev Respir Dis 1983; 127: 270-277.

20 Rosenthal M, Cramer D, Bain SH, et al. Lung function in white children aged 4 to 19 years: II - single breath analysis and plethysmograpy. Thorax 1993; 48: 803-808.

21 Polgar G, Promadhat V. Pulmonary Function Tests in Children: Techniques and Standards. Philadelphia, Saunders, 1971.

22 Koopman M, Zanen P, Kruitwagen CL, et al. Reference values for paediatric pulmonary function testing: the Utrecht dataset. Respir Med 2011; 105: 15-23.

23 Kim YJ, Hall GL, Christoph K, et al. Pulmonary diffusing capacity in healthy Caucasian children. Pediatr Pulmonol 2012; 47: 469-475.

24 Thomas A, Hanel B, Marott JL, et al. The single-breath diffusing capacity of CO and NO in healthy children of European descent. PLoS One 2014; 9: e113177.

25 Michailopoulos P, Kontakiotis T, Spyratos D, et al. Reference equations for static lung volumes and TLCO from a population sample in northern Greece. Respiration 2015; 89: 226-234.

26 Thompson BR, Johns DP, Bailey M, et al. Prediction equations for single breath diffusing capacity (TLCO) in a middle aged caucasian population. Thorax 2008; 63: 889-893.

27 Garcia-Rio F, Dorgham A, Galera R, et al. Prediction equations for single-breath diffusing capacity in subjects aged 65 to 85 years. Chest 2012; 142: 175-184.

28 Gutierrez C, Ghezzo RH, Abboud RT, et al. Reference values of pulmonary function tests for Canadian Caucasians. Can Respir J 2004; 11: 414-424.

29 Quanjer PH, Kubota M, Kobayashi H, et al. Secular changes in relative leg length confound height-based spirometric reference values. Chest 2015; 147: 792-797. 
30 Collard P, Njinou B, Nejadnik B, et al. Single breath diffusing capacity for carbon monoxide in stable asthma. Chest 1994; 105: 1426-1429.

31 Hughes JM, Pride NB. Examination of the carbon monoxide diffusing capacity (DLCO) in relation to its KCO and VA components. Am J Respir Crit Care Med 2012; 186: 132-139.

32 Sansores RH, Abboud RT, Kennell C, et al. The effect of menstruation on the pulmonary carbon monoxide diffusing capacity. Am J Respir Crit Care Med 1995; 152: 381-384.

33 Thompson BR, Kim Prisk G, Peyton P, et al. Inhomogeneity of ventilation leads to unpredictable errors in measured DLCO. Respir Physiol Neurobiol 2005; 146: 205-214.

34 Macintyre N, Crapo RO, Viegi G, et al. Standardisation of the single-breath determination of carbon monoxide uptake in the lung. Eur Respir J 2005; 26: 720-735.

35 Ruíz-Argüelles GJ, Sánchez-Medal L, Loría A, et al. Red cell indices in normal adults residing at altitude from sea level to 2670 meters. Am J Hematol 1980; 8: 265-271.

36 Cotes JE, Chinn DJ, Quanjer PH, et al. Standardization of the measurement of transfer factor (diffusing capacity). Eur Respir J 1993; 6: Suppl. 16, 41-52.

37 Cotes JE, Dabbs JM, Elwood PC, et al. Iron-deficiency anaemia: its effect on transfer factor for the lung (diffusing capacity) and ventilation and cardiac frequency during sub-maximal exercise. Clin Sci 1972; 42: 325-335.

38 Beutler E, Waalen J. The definition of anemia: what is the lower limit of normal of the blood hemoglobin concentration? Blood 2006; 107: 1747-1750.

39 Kang MY, Sapoval B. Time-based understanding of DLCO and DLNO. Respir Physiol Neurobiol 2016; 225: 48-59. 